\title{
Acute Impact of the Coronavirus Disease Outbreak on Behavioral Patterns and Emotional States of Pediatric Psychiatric Patients and Caregivers in Daegu, South Korea
}

\author{
Hye Rin Seo', Hyun Seok Jung², Da Seul Jung², Jeong Won $\mathrm{Choi}^{2}$, and So Hye $\mathrm{Jo}^{2 凶}$ \\ ${ }^{1}$ Department of Medicine, Yonsei University College of Medicine, Seoul, Republic of Korea \\ ${ }^{2}$ Department of Psychiatry, Yeungnam University Medical Center, Daegu, Republic of Korea
}

\begin{abstract}
Objective This study aimed to investigate the changes in interpersonal relationships, behavioral patterns, and emotional states of children and adolescents with psychiatric disorders and their caregivers immediately after the coronavirus disease of 2019 (COVID-19) outbreak in Daegu, South Korea.

Methods A total of 147 patients and 147 caregivers participated in the Survey for Outing and Time Usage for Child, Adolescent, and Parents and the COVID-19 Visual Analog Scale for Emotion. We classified the patients and their caregivers into the internalizing disorder (ID) and externalizing disorder (ED) groups and compared the changes.

Results Parent-child relationships for adolescent patients and caregivers were interrupted, and friend relationships in all participants were disrupted, while sibling relationships improved in adolescent patients. They experienced negative emotional changes. Time spent outdoor decreased and digital screen time increased for all participants. Friend and parent-child relationships were interrupted in the ED group compared to those in the ID group. ED patients experienced negative changes in emotional states, while ID patients showed no significant changes.

Conclusion Results are meaningful as a reference for predicting changes in interpersonal relationships and mental status of pediatric psychiatric patients and for determining healthcare system adaptations to allow mental health support during the COVID-19 outbreak.

Psychiatry Investig 2021;18(9):913-922

Keywords COVID-19; Relationships; Behavioral and emotional change; Children and adolescents with psychiatric disorders; Caregivers.
\end{abstract}

\section{INTRODUCTION}

Since the end of 2019, the outbreak coronavirus disease of 2019 (COVID-19), which emerged in Wuhan, China, has spread worldwide and became an international public health emergency. ${ }^{1}$ The first large outbreak of COVID-19 outside China was reported in Daegu, South Korea on February 18, 2020. ${ }^{2}$ Due to a rapid local outbreak, on March 15, 2020, the Daegu area was declared a "special disaster area." As the number of COVID-19 cases increased, Korean public health authorities

\footnotetext{
Received: April 10, 2021 Revised: June 19, 2021

Accepted: July 30, 2021

$\triangle$ Correspondence: So Hye Jo, MD, PhD

Department of Psychiatry, Yeungnam University Medical Center, 170 Hyeonchung-ro, Nam-gu, Daegu 42415, Republic of Korea

Tel: +82-53-620-3920, Fax: +82-53-657-3921, E-mail: pure_sky@naver.com

(ac) This is an Open Access article distributed under the terms of the Creative Commons Attribution Non-Commercial License (https://creativecommons.org/licenses/bync/4.0) which permits unrestricted non-commercial use, distribution, and reproduction in any medium, provided the original work is properly cited.
}

implemented strict epidemic prevention measures such as social distancing, school closures, and home quarantine. ${ }^{3}$ Until March 30, 2020, 82.0\% of all COVID-19 cases in South Korea were reported from Daegu and the North Gyeongsang province, creating an atmosphere of confusion and fear. School opening, which was initially scheduled on March 2, 2020 was postponed five times; finally, on May 20, 2020, students of some grades started attending school again. During the five postponements, students and their parents were confused due to uncertain academic schedules and unfamiliar online education, which started on April 9, 2020. School closure was an unprecedented situation that substantially disrupted the daily lives of students and their families. ${ }^{4}$ COVID-19 outbreak, children's routine was drastically disrupted due to the closure of schools and lack of outdoor activities, resulting in limited connection with classmates and friends, absence of a day-to-day schedule, and increased sedentary behaviors and screen time. ${ }^{5}$ Since daily routines such as maintaining physical activity and social in- 
teractions are major factors in protecting the mental health of children and adolescents, it is necessary to evaluate the changes and their effects.

The COVID-19 pandemic has had a profound impact on the emotional health of individuals. During pandemics, fear and anxiety are common psychological consequences due to socioeconomic stress and concerns of being infected and infecting others, resulting in hygienic and avoidance behaviors. ${ }^{6,7}$ Children and adolescents have limited coping abilities and lack proper emotional reactions; therefore, they are vulnerable to such stressful socioenvironmental changes and have a higher risk of developing mental health problems. ${ }^{8}$ In addition, epidemic prevention measures, including social distancing and school closures, may directly interrupt their daily routine lives and social interactions, resulting in a negative impact on their emotional states. ${ }^{9}$

Children and adolescents with pre-existing psychiatric disorders might be particularly vulnerable to social distancing due to poor coping abilities toward stressful events. ${ }^{10}$ Due to the closure of school and institutional care, some them may lose access to health services, including mental health services, which are provided in school settings. Additionally, parents are an important resource for the development of children and adolescents, and caregiver's mental health status is an important predictor of children's mental health outcomes, especially in emergencies. ${ }^{11}$ Parents had increased concerns about financial difficulties and their health, and had to adapt to a new way of working from home. Parents suddenly feel pressured to take care of their children all day long, while at the same time guiding their children's digital home schooling. These stresses can cause parental negative feelings and family instability, which can exacerbate children's emotional and behavioral problems. ${ }^{12,13}$ Therefore, it is important to elucidate the changes in the behavioral and emotional states of children and adolescents with psychiatric disorders to determine interventions for these patients. Also, it is important to evaluate the emotional state of caregivers to effectively manage pediatric mental health. ${ }^{14}$ Several studies have investigated the mental health of children and adolescents during the COVID-19 outbreak..$^{12,15-17}$ However, there is little has been published about the psychological impact of the social distancing and restrictions due to COVID-19 in children and adolescents with a pre-existing mental disorders. To the best of our knowledge, there are only few studies on the emotional and behavioral changes in children and adolescents with psychiatric disorders and their caregivers due to unexpected social distancing and school closures after the onset of the COVID-19 outbreak. $^{18-23}$

The purpose of this study is to investigate the immediate changes in relationships, behavioral patterns and emotional states of children and adolescents with psychiatric disorders and their caregivers during the implementation of high-intensity social distancing associated COVID-19 outbreak in Daegu, South Korea. We evaluated subjective of changes in family and social relationships, global and specific emotions of patients and caregivers. And, we evaluated the change in behaviors (time spent out, digital screen time) rated in minutes. We formulate a hypothesis that social distancing due to COVID-19 is associated with disruptive emotional and behavior impact to children, adolescent and parents.

\section{METHODS}

\section{Design and subjects}

This single-center, cross-sectional study was conducted at Yeunggnam University Medical Center, Daegu, South Korea. The participants were patients aged 6-18 years and their caregivers who visited the Department of psychiatry at Yeunggnam university medical center for treatment from April 8 to May 12, 2020. Participants were screened based on the inclusion and exclusion criterias after treated by a pediatric psychiatrist. Before completing the questionnaires, all participants were briefed on the study purpose and contents, and they voluntarily provided consent to participate in the study. The key exclusion criteria were history of acute stress disorder or post-traumatic stress disorder, history of abuse or neglect in six months, inability to assess their own condition (IQ $<60$, ASD level II or III, prominent psychotic features, and young patients who could not understand the questionnaires with help from a clinical psychologist), and incorrect responses to the questionnaires. Patients who missed schools for more than one-fourth of the attendance days in the last semester and those not attending schools or attending alternative schools were also excluded. The study protocol was approved by the Institutional Review Board (IRB) of Yeunggnam University Hospital (IRB File No. 2020-06-050-002).

\section{Procedure and assessment tools}

Subjects were instructed to complete the Survey for Outing and Time Usage for Child, Adolescent, and Parents (SOTCAP) and the COVID-19 Visual Analog Scale for Emotion (C-VASE) at the outpatient visits. Children, adolescents, and caregivers answered to the questionnaire individually. Two professional clinical psychologists prepared and explained the questionnaire. If a young child could not understand the written questions, the clinical psychologists read the question and guided the child to mark the most appropriate place for his or her condition.

Patients were classified using an internalizing-externalizing model. Internalizing disorders (ID) include major depressive 
disorders and mood disorders, such as dysthymia and anxiety disorders. Externalizing disorders (ED) include attentiondeficit/hyperactivity disorder (ADHD), oppositional defiant disorder, and conduct disorders. ${ }^{24-26}$

\section{Measurements}

\section{SOTCAP}

This questionnaire was composed of four parts. In the first part, we evaluated demographic data on date of birth, sex, school attendance, school grade, and number of family members. In the second part, we evaluated the presence of COVID-19-related symptoms (for example, fever, sore throat, and myalgia) and experience of direct or indirect contact with COVID-19-positive patients. In the third part, participants were asked to rate the changes in social relationships and family relationships during the last month using a Likert scale, with scores ranging from 1 to 5 ( $1=$ very bad, $2=$ bad, $3=$ =no change, $4=$ improved, $5=$ =very good). Higher scores indicated a positive change in relationships. In the last part, participants were asked to report the digital screen time, time spent outdoors, and sleeping patterns. All variables are required to report the status before social distancing due to COVID-19 pandemic and past two weeks, respectively ("Has there been any change in the following activities in the last 2 weeks compared to usual?"). Digital screen time includes time spent playing games, usage of social network service (SNS), and watching video media (for example, YouTube, Netflix), and etc. They were asked to report usage in minutes for each item. The time spent outdoors is intended to assess an individual's level of restriction pertaining to routine activities, with the average time spent outside the home to perform any activities. They were asked to report in minutes by morning, afternoon and evening. Sleeping patterns includes the time to go to bed, the time to go to sleep, the time to wake up, and the frequency of waking up.

\section{C-VASE}

C-VASE was designed to compare global emotional states and specific emotional states during the past 2 weeks and the time before the COVID-19 outbreak with reference to visual analogue mood scales. ${ }^{27-29}$ The visual analogue method has the advantage of being able to report one's own status more intuitively and easily instead of verbally evaluating emotions. C-VASE evaluates the global emotional state and specific emotional states. The global emotional state is marked with 0 (most active state) and 100 (completely exhausted state) at the extremes, and reference points are divided into 10 units. The horizontal line represents the face picture of the expression in which the emotion becomes stronger according to the positive/negative direction based on 50. Participants are asked to indicate their emotional state on a scale of $0-100$. For specific emotional states (afraid, confused, sad, angry, energetic, and tired), a face picture depicting each emotion is displayed on the left, and horizontal lines separated by 7 vertical lines ranging from 'not feeling at all' to 'moderate feeling' to 'severe feeling' are presented on the right side of the face picture. Participants are required to mark the intensity of each emotion on a horizontal line using a 7-point Likert scale. In this study, the Cronbach $\alpha$ value of the global emotional state was 0.817 and the specific emotional state was 0.946 , indicating a good level of reliability.

\section{Statistical analysis}

The dataset was analyzed using SPSS version 24.0 (IBM Corp., Armonk, NY, USA). Descriptive statistics were used to describe the participants' demographic data. A one-sample ttest was used to evaluate the changes in relationships in each group. The independent $t$-test and analysis of variance (ANOVA) test were performed to compare the changes in relationships between different groups. Using a paired t-test, we analyzed changes in behavioral patterns, including outing time and mobile phone usage time. The repeated measures ANOVA test was used to compare changes in outing time, mobile phone usage time, and C-VASE scores between groups. The statistical significance level was set at $\mathrm{p}<0.05$. Bonferroni correction was used for multiple comparison analysis.

\section{RESULTS}

A total of 41 child patients, 106 adolescent patients, and 147 caregivers were participated. Patients' demographic data are summarized in Tables 1 and 2 . We classified patients into three groups according to the type of disorder (externalizing disorder [ED], internalizing disorder [ID], and other disorders [OD]), and performed statistical analysis in the ED and ID groups. Changes in social and family relationships after the COVID-19 outbreak are summarized in Table 3. For child patients, relationships with friends were significantly disrupted $(p<0.05)$, while there were no significant changes in relationships with parents and siblings. In adolescents, relationships with parents and friends worsened $(p<0.05)$, while that with siblings improved $(\mathrm{p}<0.05)$. In caregivers, parent-child, friend, and social relationships deteriorated $(\mathrm{p}<0.05)$, while marital relationships did not change significantly. There were no significant differences in the changes in relationships between the three groups.

Time spent outdoors and digital screen time before and after the COVID-19 outbreak are shown in Table 4. Child and adolescent patients spent less time outside in the morning, 
Impact of COVID-19 on Patients and Caregivers

Table 1. Demographic data of study participants

\begin{tabular}{|c|c|c|c|c|}
\hline & $\begin{array}{c}\text { Children }(\mathrm{N}=41) \\
\text { Mean }(\mathrm{SD})\end{array}$ & $\begin{array}{c}\text { Adolescents }(\mathrm{N}=106) \\
\text { Mean }(\mathrm{SD})\end{array}$ & $\begin{array}{c}\text { Caregivers }(\mathrm{N}=147) \\
\text { Mean }(\mathrm{SD})\end{array}$ & $\begin{array}{c}\text { Total }(\mathrm{N}=294) \\
\text { Mean }(\mathrm{SD})\end{array}$ \\
\hline Age in years & $9.53(2.82)$ & $15.41(0.76)$ & $45.71(9.60)$ & $29.98(17.58)$ \\
\hline \multicolumn{5}{|l|}{ Gender (N [\%]) } \\
\hline Male & $28(68.29)$ & $45(42.45)$ & $17(11.56)$ & $90(30.61)$ \\
\hline Female & $7(17.07)$ & $42(39.62)$ & $104(70.74)$ & $153(52.04)$ \\
\hline None* & $6(14.63)$ & $19(17.92)$ & $26(17.69)$ & $51(17.35)$ \\
\hline Education years & $3.34(2.86)$ & $8.02(0.52)$ & $10.95(6.46)$ & $8.83(5.97)$ \\
\hline \multicolumn{5}{|l|}{ Sleep (minutes) } \\
\hline Total sleep time & $555.88(71.78)$ & $525.52(158.66)$ & $500.67(515.16)$ & $517.43(377.03)$ \\
\hline Sleep latency & $30.73(34.52)$ & $36.56(3.85)$ & $29.03(33.05)$ & $31.98(39.61)$ \\
\hline
\end{tabular}

*no response. $\mathrm{SD}$, standard deviation

Table 2. Demographic data of children and adolescents by groups

\begin{tabular}{|c|c|c|c|c|}
\hline & $\begin{array}{c}\text { ED } \\
(\mathrm{N}=71) \\
\text { Mean }(\mathrm{SD})\end{array}$ & $\begin{array}{c}\text { ID } \\
(\mathrm{N}=45) \\
\text { Mean }(\mathrm{SD})\end{array}$ & $\begin{array}{c}\text { OD } \\
(\mathrm{N}=31) \\
\text { Mean }(\mathrm{SD})\end{array}$ & $\begin{array}{c}\text { Total } \\
(\mathrm{N}=147) \\
\text { Mean }(\mathrm{SD})\end{array}$ \\
\hline Age in years & $12.36(3.65)$ & $15.21(2.18)$ & $14.54(3.41)$ & $13.53(3.48)$ \\
\hline \multicolumn{5}{|c|}{ Gender $[N(\%)]$} \\
\hline Male & $42(59.50)$ & $16(35.60)$ & $15(48.38)$ & $73(49.66)$ \\
\hline Female & $15(21.10)$ & $24(53.30)$ & $10(32.25)$ & $49(33.33)$ \\
\hline None & $14(19.70)$ & $5(11.10)$ & $6(19.35)$ & $25(17.01)$ \\
\hline
\end{tabular}

SD, standard deviation; ED, externalizing group; ID, internalizing group; OD, other disorders group

afternoon, and evening after the outbreak $(\mathrm{p}<0.05)$. For caregivers, the time spent outdoors was reduced in the morning and afternoon $(\mathrm{p}<0.05)$, but not in the evening. However, for caregivers, the time spent outdoors was significantly reduced in the morning and afternoon ( $<<0.05)$, but not in the evening. Digital screen time was classified into time spent on playing games, using SNS, watching video media and other usage. For child and adolescent patients, the time spent for playing games increased $(\mathrm{p}<0.05)$, and for child patients and caregivers, the time spent watching video media increased $(\mathrm{p}<0.05)$. There were no significant differences in changes in the time spent on playing games, using SNS, watching video media, and other usage among the three groups.

Changes in the C-VASE scores after the COVID-19 outbreak are summarized in Table 5. Child patients $(\mathrm{p}<0.05)$ and caregivers $(\mathrm{p}<0.001)$ showed a significant increase in global emotional scores, indicating negative changes, while adolescent patients showed no significant changes. Changes in global emotional scores were not significantly different among the three groups. Specifically, C-VASE scores for sad increased in child patients $(p<0.05)$, while scores for confused and angry increased $(p<0.05)$ and those for energetic decreased $(p<0.001)$ in adolescent patients. In caregivers, all six specific emotion- al scores (afraid, confused, sad, angry, energetic, and tired) changed negatively after the outbreak. There were significant differences in scores for afraid, confused, sad, angry, and tired between the three groups, which was attributed to the changes in the scores among caregivers.

Table 6 shows changes in relationships after the outbreak between the ED and ID groups. For ED patients, parent-child and friend relationships were disrupted, while sibling relationship improved $(p<0.05)$. There were no significant changes in relationships in ID patients. There were no significant differences in changes in relationship between the two groups.

Table 7 presents changes of C-VASE scores after the COVID-19 outbreak between the ED and ID groups. According to the global emotional score, ED patients felt significantly increased bad emotion, but there were significant differences in the global emotional score among ID patients. ID patients showed significantly higher scores than ED patients in all specific emotional scores $(\mathrm{p}<0.05)$, except those for angry and energetic. ED patients showed significant increase in global emotional scores $(\mathrm{p}<0.05)$. ED patients were significantly more afraid, confused, sad, angry, and less energetic after the COVID-19 outbreak $(\mathrm{p}<0.05)$. However, ID patients showed no significant changes in all specific emotional scores. There were no significant differences in changes in specific emotional scores between the groups.

\section{DISCUSSION}

In the current study, we found that relationships, behavioral patterns, and emotional states of children and adolescents with psychiatric disorders and their caregivers changed immediately after the COVID-19 outbreak. During the period of high-intensity social distancing, children and adolescents and their caregivers experienced negative emotions, and increased sedentary behaviors and digital screen time. 
Due to high-intensity social distancing, social relationships were strongly limited to close family members. Increased time spent at home can alter friendship and family relationships. For children and adolescents, relationships are particularly important as it is a time when identity develops and lifetime trajectories of emotional and behavioral problems are created. ${ }^{30,31}$ Rogers et al. ${ }^{32}$ reported an increase in family support and a slight decrease in family conflict in US adolescents during the COVID-19 outbreak. However, Prime et al. ${ }^{33}$ have suggested that the outbreak can negatively affect parent-child re-

Table 3. Changes in interpersonal relationships of children and adolescent patients and their caregivers after COVID-19 outbreak

\begin{tabular}{|c|c|c|c|c|c|}
\hline & $\begin{array}{c}\text { Children }(\mathrm{N}=41) \\
\text { Mean }(\mathrm{SD})\end{array}$ & $\begin{array}{c}\text { Adolescents }(\mathrm{N}=106) \\
\text { Mean }(\mathrm{SD})\end{array}$ & $\begin{array}{c}\text { Caregivers }(\mathrm{N}=147) \\
\text { Mean }(\mathrm{SD})\end{array}$ & t or $F$ & p value ${ }^{\dagger}$ \\
\hline \multicolumn{6}{|c|}{ Relationship change } \\
\hline Parents-child & $2.68(1.38)$ & $2.42(1.50)^{*}$ & $2.41(1.33)^{*}$ & 0.642 & 0.527 \\
\hline Friends & $2.41(1.39)^{*}$ & $2.56(1.45)^{*}$ & $2.36(1.27)^{*}$ & 0.653 & 0.521 \\
\hline Siblings & $3.07(0.68)$ & $3.20(0.71)^{*}$ & & 0.604 & 0.439 \\
\hline Marital & & & $2.97(0.47)$ & & \\
\hline Social & & & $2.86(0.52)^{*}$ & & \\
\hline
\end{tabular}

${ }^{*} \mathrm{p}<0.05$ derived from one sample $\mathrm{t}$ test; ${ }^{\dagger} \mathrm{p}$ values derived from independent $\mathrm{t}$ test or analysis of variance. COVID-19, coronavirus disease of 2019; SD, standard deviation

Table 4. Comparison of changes in outing activity and smartphone usage time of children and adolescents patients and their caregivers before the COVID-19 outbreak and in the last two weeks

\begin{tabular}{|c|c|c|c|c|}
\hline & $\begin{array}{c}\text { Children }(\mathrm{N}=41) \\
\text { Mean }(\mathrm{SD})\end{array}$ & $\begin{array}{c}\text { Adolescents }(\mathrm{N}=106) \\
\text { Mean }(\mathrm{SD})\end{array}$ & $\begin{array}{c}\text { Caregivers }(\mathrm{N}=147) \\
\text { Mean }(\mathrm{SD})\end{array}$ & $\begin{array}{c}\mathrm{p} \mathrm{value}^{\dagger} \\
(\text { period } \times \text { group })\end{array}$ \\
\hline \multicolumn{5}{|c|}{ Outing time (minute) } \\
\hline Morning & & & & 0.003 \\
\hline Before & $83.41(148.72)$ & $81.37(155.41)$ & $88.09(167.31)$ & \\
\hline Recent & $23.41(100.28)^{* *}$ & $14.72(49.03)^{* * *}$ & $68.29(158.47)^{* * *}$ & \\
\hline Afternoon & & & & 0.243 \\
\hline Before & $107.80(135.47)$ & 95.19 (131.49) & $110.40(143.74)$ & \\
\hline Recent & $39.17(63.39)^{* *}$ & $54.06(94.47)^{* *}$ & $79.11(134.18)^{\star \star}$ & \\
\hline Evening & & & & 0.758 \\
\hline Before & $17.80(41.62)$ & $33.40(87.28)$ & $35.30(91.41)$ & \\
\hline Recent & $1.46(9.37)^{* *}$ & $17.64(49.81)^{*}$ & $25.64(83.03)$ & \\
\hline \multicolumn{5}{|c|}{ Mobile phone usage time (minute) } \\
\hline Game & & & & 0.061 \\
\hline Before & $46.34(77.32)$ & $45.47(80.10)$ & $9.80(34.07)$ & \\
\hline Recent & $67.56(97.31)^{*}$ & $74.10(168.09)^{*}$ & $13.26(46.86)$ & \\
\hline SNS & & & & 0.584 \\
\hline Before & $5.85(22.47)$ & $68.96(124.84)$ & $30.74(76.04)$ & \\
\hline Recent & $6.34(22.56)$ & $64.34(125.67)$ & $35.85(100.59)$ & \\
\hline Video media & & & & 0.138 \\
\hline Before & $71.46(98.121)$ & $78.81(140.76)$ & $31.76(73.575)$ & \\
\hline Recent & $118.53(156.32)^{*}$ & $86.04(138.74)$ & $48.23(100.74)^{* *}$ & \\
\hline Others & & & & 0.709 \\
\hline Before & $2.93(13.09)$ & $20.38(67.22)$ & $33.74(66.02)$ & \\
\hline Recent & $6.46(26.23)$ & $23.30(82.12)$ & $32.51(55.54)$ & \\
\hline
\end{tabular}

${ }^{*} \mathrm{p}<0.05 ;{ }^{* *} \mathrm{p}<0.01 ;{ }^{* * *} \mathrm{p}<0.001 ; \mathrm{p}$ values for change before Special disaster area declared in COVID-19 were derived from paired $\mathrm{t}$ test; ${ }^{\dagger} \mathrm{p}$ values for period $\times$ group were derived from repeated measure analysis of variance between group and period. COVID-19, coronavirus disease of 2019; SD, standard deviation; SNS, social networking service 
lationships due to psychological distress on caregivers during the pandemic, resulting in problematic parenting behaviors. They have also suggested that sibling relationships may suffer due to altered parenting behavior, causing sibling rivalry. In this study, friend relationships were disrupted in patients and caregivers, while changes in family relationships were more complicated. Parent-child relationships were disrupted in adolescent patients and caregivers, while sibling relationships improved for adolescent patients, but it did not change for child patients. Sibling relationship may have improved in the process of performing tasks, solving problems together, and effectively responding to the traumatic experience during the pandemic when they spend more time together. ${ }^{34}$ There was a similar result of the sibling to siblings relationship showing positive trends during the COVID-19 pandemic. ${ }^{35}$ These results could be understood as the sibling has more opportunities to interact than usual, share thoughts and concerns, com-

Table 5. Comparison of changes in visual analog scale for emotion of children and adolescent patients and their caregivers before COVID-19 outbreak and in the last two weeks

\begin{tabular}{|c|c|c|c|c|}
\hline & $\begin{array}{l}\text { Children } \\
(\mathrm{N}=41) \\
\text { Mean }(\mathrm{SD})\end{array}$ & $\begin{array}{l}\text { Adolescents } \\
(\mathrm{N}=106) \\
\text { Mean (SD) }\end{array}$ & $\begin{array}{l}\text { Caregivers } \\
(\mathrm{N}=147) \\
\text { Mean }(\mathrm{SD})\end{array}$ & $\begin{array}{c}\mathrm{p} \text { value } \\
\text { (period } \times \\
\text { group) }\end{array}$ \\
\hline Global & & & & 0.098 \\
\hline Before & $26.83(27.24)$ & $30.57(27.73)$ & $34.83(24.62)$ & \\
\hline Recent & $35.37(27.49)^{*}$ & *33.68 (28.02) & $43.59(27.80)^{* * *}$ & \\
\hline Afraid & & & & 0.023 \\
\hline Before & $1.98(1.77)$ & $2.63(4.98)$ & $2.16(1.57)$ & \\
\hline Recent & $2.46(1.75)$ & $2.50(1.98)$ & $3.10(1.98)^{* * *}$ & \\
\hline Confused & & & & $<0.001$ \\
\hline Before & $1.98(1.62)$ & $2.18(1.90)$ & $2.12(1.58)$ & \\
\hline Recent & $2.07(1.63)$ & $2.51(2.06)^{*}$ & $3.03(1.93)^{* * *}$ & \\
\hline Sad & & & & 0.002 \\
\hline Before & $2.15(1.67)$ & $2.50(1.98)$ & $2.21(1.58)$ & \\
\hline Recent & $2.34(1.80)^{*}$ & $2.65(2.12)$ & $2.89(2.06)^{* * *}$ & \\
\hline Angry & & & & 0.025 \\
\hline Before & $2.68(2.09)$ & $2.52(2.02)$ & $2.29(1.63)$ & \\
\hline Recent & $3.12(2.20)$ & $2.78(2.11)^{*}$ & $3.01(2.04)^{* * *}$ & \\
\hline Energetic & & & & 0.211 \\
\hline Before & $3.66(2.19)$ & $3.35(2.13)$ & $3.26(1.84)$ & \\
\hline Recent & $3.54(1.95)$ & $2.86(2.00)^{* * *}$ & $3.03(1.67)^{*}$ & \\
\hline Tired & & & & 0.026 \\
\hline Before & $2.63(1.97)$ & $3.31(2.19)$ & $3.32(1.93)$ & \\
\hline Recent & $2.90(1.77)$ & $3.41(2.28)$ & $3.87(2.16)^{* * *}$ & \\
\hline
\end{tabular}

${ }^{*} \mathrm{p}<0.05 ;{ }^{* *} \mathrm{p}<0.01 ;{ }^{* *} \mathrm{p}<0.001 ; \mathrm{p}$ values for change before Special disaster area declared in COVID-19 were derived from paired $t$ test; ${ }^{\dagger} p$ values for period $\times$ group were derived from repeated measure analysis of variance between group and period. COVID-19, coronavirus disease of 2019; SD, standard deviation municate better, and understand each other better.

The childhood and adolescent populations are more vulnerable to increased screen time with lesser self-control and likely to have long-term consequences. ${ }^{36}$ For this reason,

Table 6. Changes in interpersonal relationship between externalizing and internalizing group participants after COVID-19 outbreak

\begin{tabular}{lcccc}
\hline & $\begin{array}{c}\mathrm{ED} \\
(\mathrm{N}=71) \\
\text { Mean (SD) }\end{array}$ & $\begin{array}{c}\text { ID } \\
(\mathrm{N}=45) \\
\text { Mean (SD) }\end{array}$ & $\mathrm{t}$ & p value $^{\dagger}$ \\
\hline Relationship change & & & & \\
Parents-child & $2.39(1.57)^{*}$ & $2.76(1.23)$ & -1.382 & 0.170 \\
Friends & $2.49(1.49)^{*}$ & $2.76(1.26)$ & -1.016 & 0.312 \\
Siblings & $3.23(0.73)^{*}$ & $3.21(0.69)$ & 0.176 & 0.861 \\
\hline
\end{tabular}

${ }^{*} \mathrm{p}<0.05$ using one sample $\mathrm{t}$ test; ${ }^{\dagger} \mathrm{p}$ values derived from independent $t$ test. COVID-19, coronavirus disease of 2019; ED, externalizing group; ID, internalizing group; SD, standard deviation

Table 7. Comparison of changes in visual analog scale for emotion between externalizing and internalizing group participants after COVID-19 outbreak

\begin{tabular}{|c|c|c|c|c|}
\hline & $\begin{array}{c}\text { ED } \\
(\mathrm{N}=71) \\
\text { Mean (SD) }\end{array}$ & $\begin{array}{c}\text { ID } \\
(\mathrm{N}=45) \\
\text { Mean (SD) }\end{array}$ & $\begin{array}{l}\mathrm{p}_{\text {value }}^{\dagger} \\
\text { (group) }\end{array}$ & $\begin{array}{l}\mathrm{p} \text { value }^{\dagger} \\
\text { (period } \\
\times \text { group) }\end{array}$ \\
\hline Global & & & 0.001 & 0.006 \\
\hline Before & $20.56(23.48)$ & $42.22(28.36)$ & & \\
\hline Recent & $30.70(26.20)^{* * *}$ & $40.22(28.00)$ & & \\
\hline Afraid & & & 0.021 & 0.138 \\
\hline Before & $1.85(1.62)$ & $3.73(7.29)$ & & \\
\hline Recent & $2.31(1.94)^{* *}$ & $2.93(1.85)$ & & \\
\hline Confused & & & 0.012 & 0.510 \\
\hline Before & $1.77(1.63)$ & $2.71(1.91)$ & & \\
\hline Recent & $2.17(1.90)^{*}$ & $2.96(2.12)$ & & \\
\hline Sad & & & $<0.001$ & 0.188 \\
\hline Before & $1.94(1.76)$ & $3.40(1.84)$ & & \\
\hline Recent & $2.21(1.97)^{*}$ & $3.40(1.97)$ & & \\
\hline Angry & & & 0.053 & 0.140 \\
\hline Before & $2.32(2.01)$ & $3.24(2.05)$ & & \\
\hline Recent & $2.83(2.14)^{* *}$ & $3.38(2.11)$ & & \\
\hline Energetic & & & 0.970 & 0.555 \\
\hline Before & $3.56(2.33)$ & $3.47(1.84)$ & & \\
\hline Recent & $3.04(2.17)^{* *}$ & $3.11(1.72)$ & & \\
\hline Tired & & & $<0.001$ & 0.926 \\
\hline Before & $2.54(2.08)$ & $3.98(1.86)$ & & \\
\hline Recent & $2.69(2.03)$ & $4.16(2.03)$ & & \\
\hline
\end{tabular}

${ }^{*} \mathrm{p}<0.05 ;{ }^{* *} \mathrm{p}<0.01 ;{ }^{* * *} \mathrm{p}<0.001 ; \mathrm{p}$ values for change before Special disaster area declared in COVID-19 were derived from paired $t$ test; ${ }^{\dagger} p$ values for group, period $\times$ group were derived from repeated measure analysis of variance between group and period. COVID-19, coronavirus disease of 2019; ED, externalizing group; ID, internalizing group; $\mathrm{SD}$, standard deviation 
there are many studies investigating the digital screen time of children and adolescents during the COVID-19 pandemic. ${ }^{37-39}$ Like many other research results, in this study, it was found that social distancing increases the sedentary behavior of children and adolescents, ${ }^{40,41}$ and decreases the engagement in outdoor activities including routine activities. ${ }^{42,43}$ In a study of Korean parents, 94 percent reported that their children's engagement in sports or play decreased during the COVID-19 pandemic. ${ }^{44}$ Increased digital screen time is associate with the increased in indoor activity and the decreased in physical activity. A retrospective study of 254 Canadian families reported an increase of screen time in mothers, fathers, and children during COVID- 19 as $74 \%, 61 \%$, and $87 \%{ }^{45} \mathrm{~A}$ study of 213 children and adolescents with ADHD reported decreased outdoor time and increased gaming during the COVID-19 pandemic. ${ }^{46}$ These digital screen time alone or in combination with other sedentary behaviors can negatively affect quality of life by detrimental effects of not only physical health but also psychological health, so it is necessary to manage. ${ }^{47}$ Currently, in a condition different from the 'situation before COVID-19 pandemic', it may be useful to facilitate peer interaction with digital socialization during social distancing. They insist that digital socialization can mitigate the effects of social distancing. ${ }^{48}$ It was found that people who maintain relationships through digital technology are less likely to experience mental health problems related to reduce in-person socialization. ${ }^{49-51}$ As much as these various views, further researches on the longterm effects of changed lifestyle and increase in digital screen time are needed..$^{52}$

For young children, efforts should be made to follow a consistent routine with enough opportunities to play, rest and engage in physical activity. ${ }^{53}$ It is recommended that family engages in indoor sports activities with the child to avoid longer durations of digital screen time. Management must be taken to avoid excessive and irresponsible use of social media or internet gaming. It will be necessary to specify the level of screen time appropriate for age through assessing sufficient evidence and consensus of experts. Sedentary behavior guidelines recommend $\leq 2 \mathrm{hr}$ of recreational screen time per day for 5-17 year-olds. ${ }^{54}$ Parents need to negotiate to limit their child's digital screen time, and to prevent sedentary behavior, planned exercises, enjoyable tasks, playing non-sedentary family games should be recommended. ${ }^{55}$

During an epidemic outbreak, people experience negative emotional responses, such as anxiety, anger, confusion, and depression symptoms..$^{56,57}$ Imran et al. ${ }^{58}$ reported that young children sense their parents' stress and may display their worries through inappropriate behaviors. They also reported that adolescents feel frustrated, nervous, and disconnected due to impaired social relationships during the outbreak. In our study, child patients experienced sadness, while adolescents were more confused, angry, and less energetic during the outbreak. Child patients may have expressed their discomfort toward parental stress and decreased activities by being sad. Adolescent patients seemed to fail to meet their desire for social activities during school lockdown, resulting in increased confusion, anger, and decreased energy. There are some studies of changes in children and adolescents with pre-existing diagnosis of mental disorder during social distancing. In our study, the emotional states of $\mathrm{ED}$ patients changed more than that of ID patients. Sciberras et al. ${ }^{46}$ have reported increased negative feelings such as sadness, depression, unhappiness, and decreased enjoyment in usual activities in children with ADHD during the COVID-19 outbreak. In another studies of children with ADHD, $34.71 \%$ experience a decreased wellbeing. ${ }^{59,60}$ They experienced increased symptoms such as irritability, depression, and difficulties in concentrating. Children and adolescents with ADHD seem to encounter special challenges. They have intolerance of uncertainty, and symptoms can be aggravated due to social restrictions or unfriendly environments and routines..$^{53}$ Home schooling requires more autonomy and motivation to establish a high level of self-discipline and newly routine. ${ }^{61}$ Since externalizing behavior is associated with impairment of self-regulation skills, they may have difficulty following instructions and performing their own work independently. As access to school or daycare becomes inaccessible, peer relationships or symptoms may worsen, with less opportunity to develop peer group interactions or social and behavioral skills. ${ }^{62}$ These conditions can trigger anger outbursts or conflicts between parents and adolescents.

Not only emotional states, but also the relationship between friends and family were different in ED and ID patients. And, changes in parent-child and friend relationships differed between the ED patients and ID patients. ED patients showed negative changes in parent-child and friend relationships, while ID patients did not show any changes in relationships. It is thought to be because the characteristics of children with $\mathrm{ED}$ are likely to be exacerbated in the context of interpersonal relationships. ${ }^{63}$ Although there were no such negative changes in ID patients, there are some points to consider. In some studies, children and adolescents with pre-existing mental illness with social anxiety disorder and learning disability showed improvement in symptoms of anxiety, depression, and irritability while transiently freeing from school-related pressures and worries with less exposure to competition and comparison with peers. ${ }^{60,64}$ However, the mitigation of these symptoms by the avoidance behavior would be non-beneficial in the long term. It is risky for students with psychological difficulties to be 'invisible' than before. ${ }^{65}$ Such masked psychological difficulties can lead to greater problems. Understanding patients' 
emotions is essential to accurately address their needs and develop relevant psychological interventions during the COVID-19 outbreak.

In emergencies like pandemic, parents are under the stress of managing their children as they adjust to a new way of life. ${ }^{66}$ During COVID-19 pandemic, it is possible that parental stress can exacerbate children's emotional and behavioral problems. ${ }^{67}$ In situations such as lockdown, the higher the parental stress, the higher the emotional and behavioral difficulties of children. ${ }^{33}$ In a similar study, it was found that the higher the stress of the family and the parent, the more externalization problems and the lesser emotional regulation in children. ${ }^{68}$

Especially, caregivers of children with psychiatric disorders may have experienced more stressful times in dealing with children who are difficult to handle. ${ }^{69}$ Amorim et al. ${ }^{70}$ reported that caregivers of children with ASD showed higher levels of anxiety than their children during the outbreak. It was found that parental stress of children with ADHD experienced higher levels of parenting stress than typically developing children. ${ }^{71}$ In our study, it was shown that caregivers experienced negative emotions before the social distancing caused by the COVID-19 pandemic. This may disturb their children due to lowered maternal acceptance and punitive attitudes toward children. Although we did not investigate the causes of negative emotions experienced by parents, in a study on parental pandemic-related stress, parents were found to be most stressed by social distancing and closure of childcare facilities and schools. ${ }^{72}$ As roles that have been dispersed and controlled through school are transferred to the home, parents may find it difficult to fulfill those roles. In addition, pandemic-related job loss, financial worries, and changes of lifestyle can affect parents' mental health. ${ }^{73}$ These parents' pandemic-related stress can result in child behavior problems, adverse childhood experience. $^{74,75}$

In this period of pandemic, parents have a great influence on the well-being of their children, so it is important to evaluate the mental health of the parents as well as the children's mental health. ${ }^{11}$ It is necessary for parents to specify how to properly cope with stress and take care of their mental health well. Like the guideline of the WHO, information on how to monitor children's emotional reactions, adjust to reduced social contacts and altered lifestyle, and coping with stress should be provided. ${ }^{1}$ And, it would be helpful to strengthen the child and youth welfare service system to reduce the burden on parents of taking care of their children and adolescents.

To the best of our knowledge, this is the first study to demonstrate changes in relationships, behavioral patterns, and emotional states in the early stages of the COVID-19 outbreak in children and adolescents with psychiatric disorders in South Korea. However, several limitations need to be considered.
First, this study included pediatric patients with psychiatric disorders; thus, it is difficult to generalize the results to general pediatric patients. Second, since the evaluation of the variables was dependent on the subject's recollection, there is a possibility that there may be a recall bias. Third, we did not assess the parents' current and past psychiatric disorders. Fourth, these results show only the acute impact of the outbreak, and further research is needed on long-term consequence after COVID-19.

In conclusion, we demonstrated that rapid environmental changes due to the COVID-19 outbreak and epidemic preventive measures had an impact on the relationships, behavioral patterns, and emotional states of children and adolescents with psychiatric disorders and their caregivers. Immediately after the outbreak, friend and parent-child relationships were disrupted, while sibling relationships improved. Time spent outdoors decreased and the digital screen time increased. All patients and caregivers experienced negative emotional changes. Patients with different types of disorders experienced an outbreak in a different way. ED patients showed more negative changes in relationships, behavioral patterns, and emotional status, while ID patients showed minimal changes during the outbreak. The results of this study could be used as a reference for predicting changes in mental health and determining healthcare system adaptations to allow mental health support during the outbreak for children and adolescents with psychiatric disorders. Although the study has limitations, this study is meaningful as it is the first to evaluate the acute impact of the COVID-19 outbreak in terms of relationships and behavioral and emotional states of South Korean children and adolescents with psychiatric disorders. Further studies on long-term emotional and behavioral changes in these patients as well as in general children and adolescents are needed.

\section{Availability of Data and Material}

The datasets generated or analyzed during the study are available from the corresponding author on reasonable request.

\section{Conflicts of Interest}

The authors have no potential conflicts of interest to disclose.

\section{Author Contributions}

Conceptualization: Hye Rin Seo, So Hye Jo. Data curation: Hye Rin Seo, Hyun Seok Jung, Da Seul Jung, Jeong Won Choi. Formal analysis: Hyun Seok Jung, Hye Rin Seo. Investigation: all authors. Methodology: Hye Rin Seo, So Hye Jo, Hyun Seok Jung. Project administration: Hye Rin Seo, So Hye Jo. Supervision: So Hye Jo. Validation: So Hye Jo. Visualization: Hye Rin Seo, Hyun Seok Jung. Writing_original draft: Hye Rin Seo. Writingreview \& editing: Hye Rin Seo, So Hye Jo.

\section{ORCID iDs}

Hye Rin Seo https://orcid.org/0000-0003-0470-6855

Hyun Seok Jung https://orcid.org/0000-0002-1613-5001

Da Seul Jung https://orcid.org/0000-0002-3079-3297 
Jeong Won Choi https://orcid.org/0000-0002-4356-4389 So Hye Jo https://orcid.org/0000-0001-9471-0713

\section{Funding Statement}

None.

\section{REFERENCES}

1. World Health Organization. World Health Organization Coronavirus Disease (COVID-19) Weekly Epidemiological Update and Weekly Operational Update; 2020. Available at: https://www.who.int/docs/default-source/coronaviruse/situation-reports/20200325-sitrep-65-covid-19.pdf?sfvrsn=ce13061b_2. Accessed March 25, 2020.

2. JH Kim. How South Korea responded to the COVID-19 outbreak in Daegu. NEJM Catal Innov Care Deliv 2020;1:1-14.

3. Jeong E, Hagose M, Jung H, Ki M, Flahault A. Understanding South Koreass Response to the COVID-19 outbreak: a real-time analysis. Int J Environ Res Public Health 2020;17:9571.

4. Korea Ministry of Health and Welfare. Regular Briefing of Central Disaster and Safety Countermeasure Headquarters on COVID-19. 2020; Available at: https://www.mohw.go.kr/eng/nw/nw0101vw.jsp?PAR_ MENU_ID $=1007 \&$ MENU_ID $=100701 \&$ page $=3 \&$ CONT SEQ=353989. Assessed February 28, 2021.

5. Xiang M, Zhang Z, Kuwahara K. Impact of COVID-19 pandemic on children and adolescents' lifestyle behavior larger than expected. Prog Cardiovasc Dis 2020;63:531-532.

6. Asmundson GJG, Taylor S. Coronaphobia: Fear and the 2019-nCoV outbreak. J Anxiety Disord 2020;70:102196.

7. Duan L, Zhu G. Psychological interventions for people affected by the COVID-19 epidemic. Lancet Psychiatry 2020;7:300-302.

8. Roussos A, Goenjian AK, Steinberg AM, Sotiropoulou C, Kakaki M, Kabakos C, et al. Posttraumatic stress and depressive reactions among children and adolescents after the 1999 earthquake in Ano Liosia, Greece. Am J Psychiatry 2005;162:530-537.

9. Jammu AS, Chasen MR, Lofters AK, Bhargava R. Systematic rapid living review of the impact of the COVID-19 pandemic on cancer survivors: update to August 27, 2020. Support Care Cancer 2021;29:2841-2850.

10. Fegert JM, Schulze UM. COVID-19 and its impact on child and adolescent psychiatry-a German and personal perspective. Ir J Psychol Med 2020;37:243-245.

11. Laor N, Wolmer L, Cohen DJ. Mothers' functioning and children's symptoms 5 years after a SCUD missile attack. Am J Psychiatry 2001;158: 1020-1026.

12. Guessoum SB, Lachal J, Radjack R, Carretier E, Minassian S, Benoit L, et al. Adolescent psychiatric disorders during the COVID-19 pandemic and lockdown. Psychiatry Res 2020;291:113264.

13. Wigman JT, Devlin N, Kelleher I, Murtagh A, Harley M, Kehoe A, et al. Psychotic symptoms, functioning and coping in adolescents with mental illness. BMC Psychiatry 2014;14:97.

14. Sun N, Wei L, Shi S, Jiao D, Song R, Ma L, et al. A qualitative study on the psychological experience of caregivers of COVID-19 patients. Am J Infect Control 2020;48:592-598.

15. Zhou SJ, Zhang LG, Wang LL, Guo ZC, Wang JQ, Chen JC, et al. Prevalence and socio-demographic correlates of psychological health problems in Chinese adolescents during the outbreak of COVID-19. Eur Child Adolesc Psychiatry 2020;29:749-758.

16. Lee J. Mental health effects of school closures during COVID-19. Lancet Child Adolesc Health 2020;4:421.

17. Odriozola-Gonzalez P, Planchuelo-Gomez A, Irurtia MJ, de Luis-Garcia R. Psychological effects of the COVID-19 outbreak and lockdown among students and workers of a Spanish university. Psychiatry Res 2020; 290:113108

18. Conte G, Baglioni V, Valente F, Chiarotti F, Cardona F. Adverse mental health impact of the COVID-19 lockdown in individuals with Tourette syndrome in Italy: an online survey. Front Psychiatry 2020;11:583744.

19. Cortese S, Asherson P, Sonuga-Barke E, Banaschewski T, Brandeis D,
Buitelaar J, et al. ADHD management during the COVID-19 pandemic: guidance from the European ADHD Guidelines Group. Lancet Child Adolesc Health 2020;4:412-414.

20. Davis C, Ng KC, Oh JY, Baeg A, Rajasegaran K, Chew CSE. Caring for children and adolescents with eating disorders in the current coronavirus 19 pandemic: a Singapore perspective. J Adolesc Health 2020;67: 131-134.

21. Tanir Y, Karayagmurlu A, Kaya I, Kaynar TB, Turkmen G, Dambasan $\mathrm{BN}$, et al. Exacerbation of obsessive compulsive disorder symptoms in children and adolescents during COVID-19 pandemic. Psychiatry Res 2020;293:113363.

22. Conti E, Sgandurra G, De Nicola G, Biagioni T, Boldrini S, Bonaventura E, et al. Behavioural and emotional changes during covid-19 lockdown in an italian paediatric population with neurologic and psychiatric disorders. Brain Sci 2020;10:918.

23. Lopez-Serrano J, Díaz-Bóveda R, González-Vallespí L, SantamarinaPérez P, Bretones-Rodríguez A, Calvo R, et al. Psychological impact during COVID-19 lockdown in children and adolescents with previous mental health disorders. Rev Psiquiatr Salud Ment (Engl Ed) 2021 [Online ahead of print]

24. Cosgrove VE, Rhee SH, Gelhorn HL, Boeldt D, Corley RC, Ehringer $\mathrm{MA}$, et al. Structure and etiology of co-occurring internalizing and externalizing disorders in adolescents. J Abnorm Child Psychol 2011;39: 109-123.

25. Hewitt JK, Rutter M, Simonoff E, Pickles A, Loeber R, Heath AC, et al. Genetics and developmental psychopathology: 1. Phenotypic assessment in the Virginia twin study of adolescent behavioral development. J Child Psychol Psychiatry 1997;38:943-963.

26. Krueger RF. The structure of common mental disorders. Arch Gen Psychiatry 1999;56:921-926.

27. Luria RE. The validity and reliability of the visual analogue mood scale. J Psychiatr Res 1975;12:51-57.

28. Machado L, Thompson LM, Brett CH. Visual analogue mood scale scores in healthy young versus older adults. Int Psychogeriatr 2019; 31:417-424.

29. Sung YT, Wu JS. The Visual Analogue Scale for Rating, Ranking and Paired-Comparison (VAS-RRP): a new technique for psychological measurement. Behav Res Methods 2018;50:1694-1715.

30. Moffitt TE, Caspi A. Childhood predictors differentiate life-course persistent and adolescence-limited antisocial pathways among males and females. Dev Psychopathol 2001;13:355-375.

31. Woodward LJ, Fergusson DM. Childhood peer relationship problems and later risks of educational under-achievement and unemployment. J Child Psychol Psychiatry 2000;41:191-201.

32. Rogers AA, Ha T, Ockey S. Adolescents' perceived socio-emotional impact of COVID-19 and implications for mental health: results from a U.S.-based mixed-methods study. J Adolesc Health 2021;68:43-52.

33. Prime H, Wade M, Browne DT. Risk and resilience in family well-being during the COVID-19 pandemic. Am Psychol 2020;75:631-643.

34. Perricone G, Fontana V, Burgio S, Polizzi C. Sibling relationships as a resource for coping with traumatic events. Springerplus 2014;3:525.

35. Zhang Y. Spending time with family members: how COVID-19 has changed the family member relationship. Proceedings of the 2020 3rd International Conference on Humanities Education and Social Sciences (ICHESS 2020); Dec 16, 2020. Atlantis Press, p.173-182.

36. Stiglic N, Viner RM. Effects of screentime on the health and well-being of children and adolescents: a systematic review of reviews. BMJ Open 2019;9:e23191.

37. Janssen X, Martin A, Hughes AR, Hill CM, Kotronoulas G, Hesketh KR. Associations of screen time, sedentary time and physical activity with sleep in under 5s: a systematic review and meta-analysis. Sleep Med Rev 2020;49:101226.

38. Hu Z, Lin X, Xu H. The impact of coronavirus disease (COVID-19) epidemic on lifestyle behaviors and their association with subjective wellbeing among the general population in the Mainland China: a crosssectional study. J Med Internet Res 2020;22:e21176. 
39. Górnicka M, Drywień ME, Zielinska MA, Hamułka J. Dietary and lifestyle changes during COVID-19 and the subsequent lockdowns among Polish adults: a cross-sectional online survey PLifeCOVID-19 study. Nutrients 2020;12:2324.

40. Margaritis I, Houdart S, El Ouadrhiri Y, Bigard X, Vuillemin A, Duché P. How to deal with COVID-19 epidemic-related lockdown physical inactivity and sedentary increase in youth? Adaptation of Anses' benchmarks. Arch Public Health 2020;78:1-6.

41. Vanderloo LM, Carsley S, Aglipay M, Cost KT, Maguire J, Birken CS. Applying harm reduction principles to address screen time in young children amidst the COVID-19 pandemic. J Dev Behav Pediatr 2020;41: 335-336.

42. Guerrero MD, Vanderloo LM, Rhodes RE, Faulkner G, Moore SA, Tremblay MS. Canadian children's and youth's adherence to the 24-h movement guidelines during the COVID-19 pandemic: A decision tree analysis. J Sport Health Sci 2020;9:313-321.

43. Moore SA, Faulkner G, Rhodes RE, Brussoni M, Chulak-Bozzer T, Ferguson LJ, et al. Impact of the COVID-19 virus outbreak on movement and play behaviours of Canadian children and youth: a national survey. Int J Behav Nutr Phys Act 2020;17:85.

44. Guan H, Okely AD, Aguilar-Farias N, del Pozo Cruz B, Draper CE, El Hamdouchi A, et al. Promoting healthy movement behaviours among children during the COVID-19 pandemic. Lancet Child Adolesc Health 2020;4:416-418.

45. Carroll N, Sadowski A, Laila A, Hruska V, Nixon M, Ma DW, et al. The impact of COVID-19 on health behavior, stress, financial and food security among middle to high income Canadian families with young children. Nutrients 2020;12:2352.

46. Sciberras E, Patel P, Stokes MA, Coghill D, Middeldorp CM, Bellgrove MA, et al. Physical health, media use, and mental health in children and adolescents with ADHD during the COVID-19 pandemic in Australia. J Atten Disord 2020 [Online ahead of print]

47. Grgic J, Dumuid D, Bengoechea EG, Shrestha N, Bauman A, Olds T, et al. Health outcomes associated with reallocations of time between sleep, sedentary behaviour, and physical activity: a systematic scoping review of isotemporal substitution studies. Int J Behav Nutr Phys Act 2018;15:69.

48. Orben A, Tomova L, Blakemore SJ. The effects of social deprivation on adolescent development and mental health. Lancet Child Adolesc Health 2020;4:634-640.

49. George MJ, Russell MA, Piontak JR, Odgers CL. Concurrent and subsequent associations between daily digital technology use and high-risk adolescents' mental health symptoms. Child Dev 2018;89:78-88.

50. Rodman AM, Rosen ML, Kasparek SW, Mayes M, Lengua L, McLaughlin KA, et al. Social behavior and youth psychopathology during the COVID-19 pandemic: a longitudinal study. PsyArXiv; 2021.

51. O'Keeffe GS, Clarke-Pearson K. The impact of social media on children, adolescents, and families. Pediatrics 2011;127:800-804.

52. Morgül E, Kallitsoglou A, Essau CAE. Psychological effects of the COVID-19 lockdown on children and families in the UK. Revista de Psicología Clínica con Niños y Adolescentes 2020;7:42-48.

53. Singh S, Roy MD, Sinha CPTMK, Parveen CPTMS, Sharma CPTG, Joshi CPTG. Impact of COVID-19 and lockdown on mental health of children and adolescents: a narrative review with recommendations. Psychiatry Res 2020;293:113429.

54. Tremblay MS, Carson V, Chaput JP, Connor Gorber S, Dinh T, Duggan $\mathrm{M}$, et al. Canadian 24-hour movement guidelines for children and youth: an integration of physical activity, sedentary behaviour, and sleep. Appl Physiol Nutr Metab 2016;41(6 Suppl 3):S311-S327.

55. Bates LC, Zieff G, Stanford K, Moore JB, Kerr ZY, Hanson ED, et al. COVID-19 Impact on behaviors across the 24-hour day in children and adolescents: physical activity, sedentary behavior, and sleep. Children (Basel) 2020;7:138.

56. Brooks SK, Webster RK, Smith LE, Woodland L, Wessely S, Greenberg $\mathrm{N}$, et al. The psychological impact of quarantine and how to reduce it: rapid review of the evidence. Lancet 2020;395:912-920.

57. Serafini G, Parmigiani B, Amerio A, Aguglia A, Sher L, Amore M. The psychological impact of COVID-19 on the mental health in the general population. QJM 2020;113:531-537.

58. Imran N, Zeshan M, Pervaiz Z. Mental health considerations for children \& adolescents in COVID-19 Pandemic. Pak J Med Sci 2020;36 (COVID19-S4):S67-S72.

59. Bobo E, Lin L, Acquaviva E, Caci H, Franc N, Gamon L, et al. How do children and adolescents with Attention Deficit Hyperactivity Disorder (ADHD) experience lockdown during the COVID-19 outbreak? Encephale 2020;46:S85-S92.

60. Zhang J, Shuai L, Yu H, Wang Z, Qiu M, Lu L, et al. Acute stress, behavioural symptoms and mood states among school-age children with attention-deficit/hyperactive disorder during the COVID-19 outbreak. Asian J Psychiatr 2020;51:102077.

61. Becker SP, Breaux R, Cusick CN, Dvorsky MR, Marsh NP, Sciberras E, et al. Remote learning during COVID-19: examining school practices, service continuation, and difficulties for adolescents with and without attention-deficit/hyperactivity disorder. J Adolesc Health 2020;67:769-777.

62. Lee J. Mental health effects of school closures during COVID-19. Lancet Child Adolesc Health 2020;4:421.

63. Feinberg ME, A Mogle J, Lee JK, Tornello SL, Hostetler ML, Cifelli JA, et al. Impact of the COVID-19 pandemic on parent, child, and family functioning. Fam Process 2021 [Online ahead of print].

64. Bruining H, Bartels M, Polderman TJ, Popma A. COVID-19 and child and adolescent psychiatry: an unexpected blessing for part of our population? Eur Child Adolesc Psychiatry 2021;30:1139-1140.

65. Cowie H, Myers CA. The impact of the COVID-19 pandemic on the mental health and well-being of children and young people. Child Soc 2020 [Epub ahead of print]

66. Fegert JM, Vitiello B, Plener PL, Clemens V. Challenges and burden of the Coronavirus 2019 (COVID-19) pandemic for child and adolescent mental health: a narrative review to highlight clinical and research needs in the acute phase and the long return to normality. Child Adolesc Psychiatry Ment Health 2020;14:20.

67. Morelli M, Cattelino E, Baiocco R, Trumello C, Babore A, Candelori C, et al. Parents and children during the COVID-19 lockdown: the influence of parenting distress and parenting self-efficacy on children's emotional well-being. Front Psychol 2020;11:584645.

68. Spinelli M, Lionetti F, Pastore M, Fasolo M. Parents' stress and children's psychological problems in families facing the COVID-19 outbreak in Italy. Front Psychol 2020;11:1713.

69. Spinelli M, Lionetti F, Setti A, Fasolo M. Parenting stress during the COVID-19 outbreak: socioeconomic and environmental risk factors and implications for children emotion regulation. Fam Process 2021;60:639653.

70. Amorim R, Catarino S, Miragaia P, Ferreras C, Viana V, Guardiano M. The impact of COVID-19 on children with autism spectrum disorder. Rev Neurol 2020;71:285-291.

71. Theule J, Wiener J, Tannock R, Jenkins JM. Parenting stress in families of children with ADHD: a meta-analysis. J Emot Behav Disord 2013;21: 3-17.

72. Calvano C, Engelke L, Di Bella J, Kindermann J, Renneberg B, Winter SM. Families in the COVID-19 pandemic: parental stress, parent mental health and the occurrence of adverse childhood experiences-results of a representative survey in Germany. Eur Child Adolesc Psychiatry 2021:1-13.

73. Frasquilho D, Matos MG, Salonna F, Guerreiro D, Storti CC, Gaspar T, et al. Mental health outcomes in times of economic recession: a systematic literature review. BMC Public Health 2015;16:115.

74. Crescentini C, Feruglio S, Matiz A, Paschetto A, Vidal E, Cogo P, et al. Stuck outside and inside: an exploratory study on the effects of the COVID-19 outbreak on Italian parents and Children's internalizing symptoms. Front Psychol 2020;11:586074.

75. Liu JJ, Bao Y, Huang X, Shi J, Lu L. Mental health considerations for children quarantined because of COVID-19. Lancet Child Adolesc Health 2020;4:347-349. 